\title{
Elevated serum lactate as a predictor of outcomes in patients following major abdominal surgery at a tertiary hospital in Uganda
}

Kiyemba Henry ${ }^{1 *}$, Kadondi Merab ${ }^{1}$, Muyanja Leonard ${ }^{1}$, Kintu-Luwaga Ronald ${ }^{2}$, Kakembo Nasser ${ }^{1}$ and Galukande Moses ${ }^{1}$

\begin{abstract}
Introduction: Major abdominal surgery is still a great contributor to postoperative morbidity and mortality in developing countries. Major abdominal surgery leads to hypoperfusion, which has an impact on postoperative morbidity and mortality. Lactate, a biomarker for hypoperfusion is under utilized in Uganda. The study aimed to investigate the association between elevated serum lactate and outcomes (in-hospital mortality, SSI and length of hospital stay) in patients following major abdominal surgery.
\end{abstract}

Methods: A prospective observational cohort study was done with 246 eligible patients recruited. Stratified sampling was carried out till desired sample size was achieved. Demographic and perioperative data were collected, serum lactate levels were measured at induction and immediately after surgery with serial measurements being done after 12, $24 \mathrm{~h}$ post operatively. Participants were followed up to assess outcomes. Data analysis was done using STATA version 14.0.

Results: A total of 130 patients (52.8\%) had elevated serum lactate levels. Elevated serum lactate predicted inhospital mortality and surgical site infection. The accuracy of elevated serum lactate to predict mortality with AUROC of 0.7898 was exhibited by the $24 \mathrm{~h}$ lactate values. Elevated serum lactate predicted surgical site infection accurately with AUROC 0.6432. Length of hospital is strongly associated with elevated serum lactate with p-value of 0.043 . Patients with elevated serum lactate on average have a longer length of hospital stay at $5.34 \pm 0.69$.

Conclusion: Elevated serum lactate was associated with in-hospital mortality, surgical site infection and longer length of hospital stay. Serum lactate levels done at $24 \mathrm{~h}$ were most predictive of mortality and surgical site infection.

Keywords: Elevated serum lactate, Major abdominal surgery, Outcome, Post-operative complications, Type of surgery

\footnotetext{
*Correspondence: kiyemba8@gmail.com

${ }^{1}$ Department of Surgery, College of Health Sciences, Makerere University, Kampala, Uganda

Full list of author information is available at the end of the article
}

\section{Introduction}

Major abdominal surgeries are performed in their millions around the world [1]. In Africa, about 143 million surgeries occur annually [2]. In East Africa, 45 operations are performed per 10,000 people [3]. Advancements in monitoring and perioperative patient care have reduced majority of the burden of postoperative complications 
and mortality. However, the greater percentage of the remaining burden is still present in the developing world. Mortality and morbidity are greatly dependent on vascular flow post operatively and compromise to this results in a wide array of outcomes [4].

Lactate has excellent sensitivity for assessing cellular damage especially from tissue hypoperfusion [5]. Elevated serum lactate or hyperlactatemia is associated with increasing rates of mortality $[6,7]$ and this necessitates prompt identification of the patients and discontinuation of the offending agent. Hyperlactatemia has an association with morbidity and Post Operative Complications (POCs) following major abdominal surgery [6-8].

Monitoring of lactate is widely used in critically ill patients such as those in Intensive Care Units (ICUs) and in patients following cardiothoracic surgery [9]. The significance of lactate monitoring in patients following major abdominal surgery, however, is still questionable especially in developing countries and there is still a deficiency in accurately and inexpensively detecting hypoperfusion in surgical patients more so following major abdominal surgery. Lactate is a potential predictor of this but is still under-utilized.

Therefore the purpose of the study was to investigate the association between hyperlactatemia and outcomes in patients following major abdominal surgery at Mulago National Referra Hospital.

\section{Methods and materials}

Prospective observational cohort study conducted at Mulago National Referral Hospital (MNRH), a public tertiary facility in Kampala, the administrative capital city of Uganda. The study population included all patients admitted to MNRH during the study period to undergo major abdominal surgery that had a diagnosis that led to major abdominal surgery who consented to participate in the study. We excluded diabetic patients on metformin from the study.

We used a sample size of 246 participants for the study with stratified sampling used and generation of sub groups as adults ( $>18$ years and above) and children (17 years and below). The proportions were in a ratio of 1:1 and consecutive sampling used within the subgroups till we acquired the desired sample size. The study variables included independent variable as hyperlactatemia: elevated serum lactate between 2 and $4 \mathrm{mmol} / \mathrm{L}$ just before surgery $\left(\mathrm{L}_{0}\right)$, immediately after surgery $\left(\mathrm{L}_{1}\right)$, after $12 \mathrm{~h}\left(\mathrm{~L}_{2}\right)$, after $24 \mathrm{~h}\left(\mathrm{~L}_{3}\right)$; dependent variables included: In-hospital mortality: death that occurred within hospital, Surgical Site Infection: infection that occur at operative wound following a surgical procedure, Length of hospital stay: time from admission till discharge or when outcome of interest was obtained. Other variables; comorbidity, time interval between diagnosis and surgical intervention, onset of symptoms, age, type of surgery, duration of surgery, treatment given, ASA status, organs/ structures involved.

We used a data collection form to acquire socio-demographic information and intra operative variables.

An initial serum lactate level at induction was obtained using a lactate meter TD-4261A - a point of care testing system for bed side testing of lactate. Blood samples for serum lactate were then collected immediately after surgery and subsequently at $12 \mathrm{~h}$ and $24 \mathrm{~h}$ following the surgery. The patients were assessed for surgical site infection and followed up till outcome of interest was achieved or up to a maximum of 30 days into the post-operative period if still admitted.

\section{Data analysis}

We entered the data into Epidata version 3.1 and subsequently analysed with STATA version 14.0 using descriptive and analytical statistics. We summarized all continuous variables following a normal distribution using means and standard deviations. Those not normally distributed were summarized using median and inter-quartile ranges. Categorical data was summarized using proportions and percentages.

We used the logistic regression to determine associations between hyperlactatemia and in-hospital mortality, Surgical site infection (SSI) and linear regression to determine association between hyperlactatemia and length of hospital stay through calculation of odds ratios (OR) and their corresponding 95\% confidence intervals (CI).

Independent variables significant at bivariate analysis at $\mathrm{p}$-value less than $0.2 \mathrm{had}$ multivariate analysis done. In multivariate analysis, we did a step wise backward method to identify significant independent variables at p-value less than 0.05. Serum lactate was assessed for interaction and confounding with the other independent variables.

The final logistic models predicting in-hospital mortality and surgical site infection had testing for goodness of fit by determining the sensitivities and specificities of lactate in predicting the outcomes. To assess accuracy we constructed Receiver Operator Curves (ROCs) and generated Area Under Receiver Operator Curves (AUROC).

\section{Ethical considerations}

We obtained approval to carry out the study from the Department of Surgery, School of Medicine Research and Ethics Committee (reference number \#REC REF 2019-094). Each study participant had written informed consent done before enrollment into the study and confidentiality ensured through the use of identification 
numbers. Informed consent was obtained from a parent or legal guardian for a participant under 18 years of age.

\section{Results}

A total of 246 patients under major abdominal surgery and were evaluated for the purpose of this study. Patients characteristics are summarized in Table 1.

\section{Outcomes}

\section{In hospital mortality}

This study observed that 34 patients died (13.8\%). Our study showed that elevated serum lactate was strongly associated with mortality (Table 2 ). Table 4 shows the prognostic value of serum lactate in predicting in-hospital mortality. Statistically, the following factors increased the risk of mortality; patients with comorbidities, duration of surgery $\geq 1.5 \mathrm{~h}$, delay between diagnosis and surgery greater than a day and finally age $>18$ years as seen in Table 2.

The ROC analysis (Fig. 1) demonstrated that elevated serum lactate was accurate in predicting in-hospital mortality and that the $24 \mathrm{~h}$ serum lactate levels had the best AUROC of 0.7898 which corresponds to good accuracy.

\section{Surgical site infection}

In this study, $14.6 \%$ of the patients developed surgical site infections. Significant factors included elevated serum lactate and lack of pre surgical treatment (Table 3). Elevated serum lactate with the prognostic value showed in Table 4 and an accuracy of 0.6432 AUROC (Fig. 2).

\section{Length of hospital stay}

Length of hospital stay was associated to elevated serum lactate (Table 5). ASA III (p-value 0.003) and duration of surgery $>1.5 \mathrm{~h}$ (p-value 0.032 ) were significantly associated with prolonged stay. Those patients with elevated serum lactate on average had a longer length of hospital stay as compared to those that had normal lactate levels (Table 6).

\section{Discussion}

We set out to investigate the association between elevated serum lactate and of outcomes in patients following major abdominal surgery at MNRH.

\section{Patient characteristics}

We found the age and gender profile similar to a study done in this setting by Kitara et al. [10] with majority of the patients being above 18 years of age and males.

We did not find comorbidity in $74.4 \%$ of the patients similar to a study done by Kitara et al., which had 78.9\% of patients with no comorbidity [10]. In our study, this
Table 1 Characteristics of 246 patients who underwent major abdominal surgery

\begin{tabular}{|c|c|c|}
\hline Characteristic $(n=246)$ & Frequency & Percentage \\
\hline \multicolumn{3}{|l|}{ Age } \\
\hline$<18$ years & 121 & 49.2 \\
\hline$\geq 18$ years & 125 & 50.8 \\
\hline \multicolumn{3}{|l|}{ Gender } \\
\hline Male & 129 & 52.4 \\
\hline Female & 117 & 47.6 \\
\hline \multicolumn{3}{|l|}{ Type of surgery } \\
\hline Elective & 62 & 25.2 \\
\hline Emergency & 184 & 74.8 \\
\hline \multicolumn{3}{|l|}{ ASA status } \\
\hline 1 & 50 & 20.3 \\
\hline$\|$ & 110 & 44.8 \\
\hline III & 82 & 33.3 \\
\hline IV & 4 & 1.6 \\
\hline \multicolumn{3}{|c|}{$\begin{array}{l}\text { Duration between diagnosis and sur- } \\
\text { gery for emergencies (days), } n=184\end{array}$} \\
\hline Within 1 day & 119 & 64.7 \\
\hline Longer than a day & 65 & 35.3 \\
\hline \multicolumn{3}{|l|}{ Duration of surgery (hours) } \\
\hline$\leq 1.5$ & 180 & 73.2 \\
\hline$>1.5$ & 66 & 26.8 \\
\hline \multicolumn{3}{|l|}{ Pre-surgery treatment } \\
\hline Yes & 52 & 21.1 \\
\hline No & 194 & 78.9 \\
\hline \multicolumn{3}{|c|}{ Intra operative treatment (litres) } \\
\hline$\leq 1$ & 94 & 38.2 \\
\hline$>1$ & 152 & 61.8 \\
\hline \multicolumn{3}{|l|}{ Comorbidities } \\
\hline No & 183 & 74.4 \\
\hline Yes & 63 & 25.6 \\
\hline \multicolumn{3}{|l|}{ Organs involved } \\
\hline One organ & 192 & 78.0 \\
\hline More than one organ & 54 & 22.0 \\
\hline \multicolumn{3}{|l|}{ Serum lactate } \\
\hline Normal ( $\leq 2.0 \mathrm{mmol} / \mathrm{L})$ & 116 & 47.2 \\
\hline $\operatorname{High}(>2.0 \mathrm{mmol} / \mathrm{L})$ & 130 & 52.8 \\
\hline
\end{tabular}

The bold was indicative of the statistically significant $\mathbf{p}$ values of different variables

This study observed the average lactate values between age groups were $3.18 \pm 0.44$ for patients less than 18 years and $2.74 \pm 0.24$ for those above 18 years

minimized the risk of confounding by comorbidities that could result in elevated serum lactate levels as stipulated by Lars et al. [11].

Our study had most surgeries as emergency cases (74.8\%) consistent with a study by Kitara et al. [10]. For the emergency cases, when diagnosis was made, 
Table 2 Factors associated with in-hospital mortality among patients who underwent major abdominal surgery at MNRH during the study period

\begin{tabular}{|c|c|c|c|c|c|c|}
\hline \multirow[t]{2}{*}{ Characteristic $(n=246)$} & \multicolumn{3}{|c|}{ Univariate } & \multicolumn{3}{|c|}{ Multivariate } \\
\hline & $\mathrm{COR}$ & $95 \% \mathrm{Cl}$ & p-value & $\mathrm{aOR}$ & $95 \% \mathrm{Cl}$ & p-value \\
\hline \multicolumn{7}{|l|}{ Age } \\
\hline$<18$ years & 1 & & & & & \\
\hline$\geq 18$ years & 0.30 & $0.21-0.43$ & $<0.001$ & 0.24 & $0.06-0.90$ & 0.034 \\
\hline \multicolumn{7}{|l|}{ Gender } \\
\hline Male & 1 & & & & & \\
\hline Female & 0.23 & $0.15-0.34$ & $<0.001$ & 0.19 & $0.06-0.64$ & 0.007 \\
\hline \multicolumn{7}{|l|}{ Type of surgery } \\
\hline Elective & 1 & & & & & \\
\hline Emergency & 2.67 & $1.98-3.60$ & $<0.001$ & 2.27 & $0.08-2.33$ & 0.331 \\
\hline \multicolumn{7}{|l|}{ ASA status } \\
\hline 1 & 1 & & & & & \\
\hline$\|$ & 2.98 & $1.09-3.87$ & 0.020 & 1.20 & $0.45-3.22$ & 0.710 \\
\hline III & 3.68 & $1.76-5.65$ & 0.001 & 2.06 & $0.74-4.96$ & 0.078 \\
\hline IV & 6.13 & $2.89-9.97$ & $<0.001$ & 2.39 & $0.13-4.18$ & 0.462 \\
\hline \multicolumn{7}{|c|}{$\begin{array}{l}\text { Duration between diagnosis \& surgery for } \\
\text { emergencies (days) }\end{array}$} \\
\hline Within 1 day & 1 & & & & & \\
\hline Longer than a day & 1.77 & $1.59-2.90$ & 0.043 & 1.45 & $1.13-1.86$ & 0.003 \\
\hline \multicolumn{7}{|l|}{ Duration of surgery (hours) } \\
\hline$\leq 1.5$ & 1 & & & & & \\
\hline$>1.5$ & 2.63 & $1.75-4.00$ & $<0.001$ & 3.17 & $1.01-9.98$ & 0.049 \\
\hline \multicolumn{7}{|l|}{ Pre-surgery treatment } \\
\hline Yes & 1 & & & & & \\
\hline No & 2.09 & $1.54-4.03$ & $<0.001$ & 1.78 & $0.29-11.11$ & 0.531 \\
\hline \multicolumn{7}{|c|}{ Intraoperative treatment (litres) } \\
\hline$\leq 1$ & 1 & & & & & \\
\hline$>1$ & 0.30 & $0.19-0.47$ & $<0.001$ & 1.51 & $0.12-2.69$ & 0.753 \\
\hline \multicolumn{7}{|l|}{ Comorbidities } \\
\hline No & 1 & & & & & \\
\hline Yes & 1.15 & $1.10-1.19$ & $<0.001$ & 1.23 & $1.11-1.36$ & $<0.001$ \\
\hline \multicolumn{7}{|l|}{ Organs involved } \\
\hline One & 1 & & & & & \\
\hline More than one organ & 1.34 & $1.20-1.50$ & $<0.001$ & 1.06 & $0.71-1.25$ & 0.675 \\
\hline \multicolumn{7}{|l|}{ Serum lactate } \\
\hline Normal $(\leq 2.0 \mathrm{mmol} / \mathrm{L})$ & 1 & & & & & \\
\hline High (> 2.0 mmol/L) & 3.79 & $2.09-6.84$ & $<0.001$ & 5.20 & $1.51-17.92$ & 0.009 \\
\hline
\end{tabular}

The bold was indicative of the statistically significant $\mathbf{p}$ values of different variables

Mortality $n=34,13.8 \%$

had surgery done within a day of diagnosis and these were $64.7 \%$ of all patients. About $78.9 \%$ of the patients

Table 3 Prognostic value of serum lactate for in-hospital mortality and SSIs

\begin{tabular}{lllll}
\hline $\begin{array}{l}\text { Characteristic } \\
\text { (serum lactate } \\
\text { for) }\end{array}$ & $\begin{array}{l}\text { Sensitivity } \\
\text { (\%) }\end{array}$ & $\begin{array}{l}\text { Specificity } \\
\text { (\%) }\end{array}$ & $\begin{array}{l}\text { Positive } \\
\text { predictive } \\
\text { value (\%) }\end{array}$ & $\begin{array}{l}\text { Negative } \\
\text { predictive } \\
\text { value (\%) }\end{array}$ \\
\hline $\begin{array}{l}\text { In-hospital } \\
\text { mortality } \\
\text { SSIs }\end{array}$ & 35.29 & 96.26 & 60.00 & 90.35 \\
\hline
\end{tabular}

requiring surgery had received no treatment prior to surgery. These can be attributed to logistical issues. However intra-operatively, $61.8 \%$ of the patients received more than $1 \mathrm{~L}$ of intravenous fluids as part of fluid therapy.

\section{Elevated serum lactate}

Of the 246 patients recruited in the study, 130 patients (52.8\%) had elevated serum lactate levels. A similar study had reference range for elevated serum lactate between 2 and $4 \mathrm{mmol} / \mathrm{L}[8]$. 

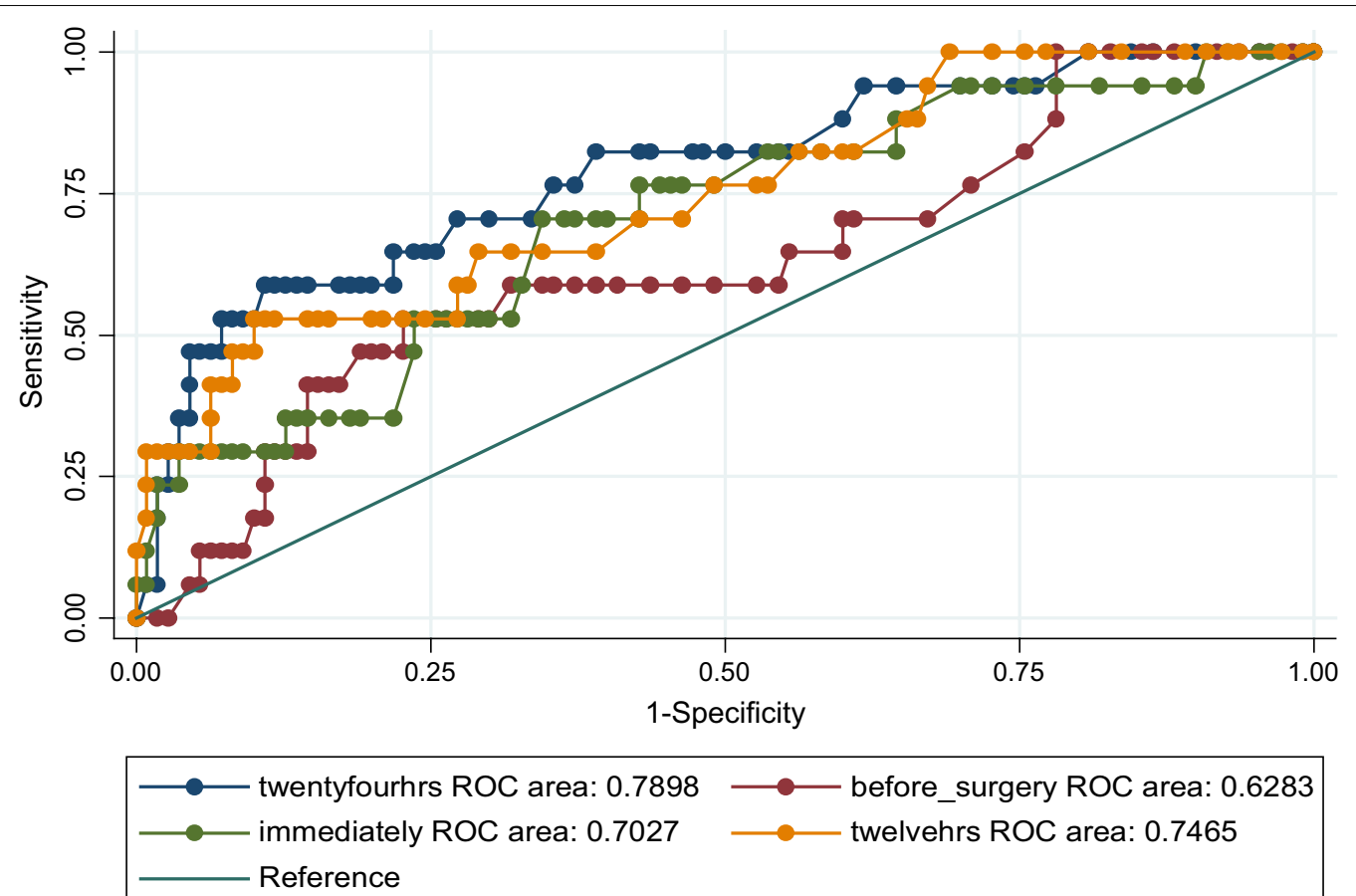

Fig. 1 ROC of serum lactate levels at four time points following major abdominal surgery in predicting mortality. $24 \mathrm{~h}$ serum lactate levels were the highest in predicting mortality

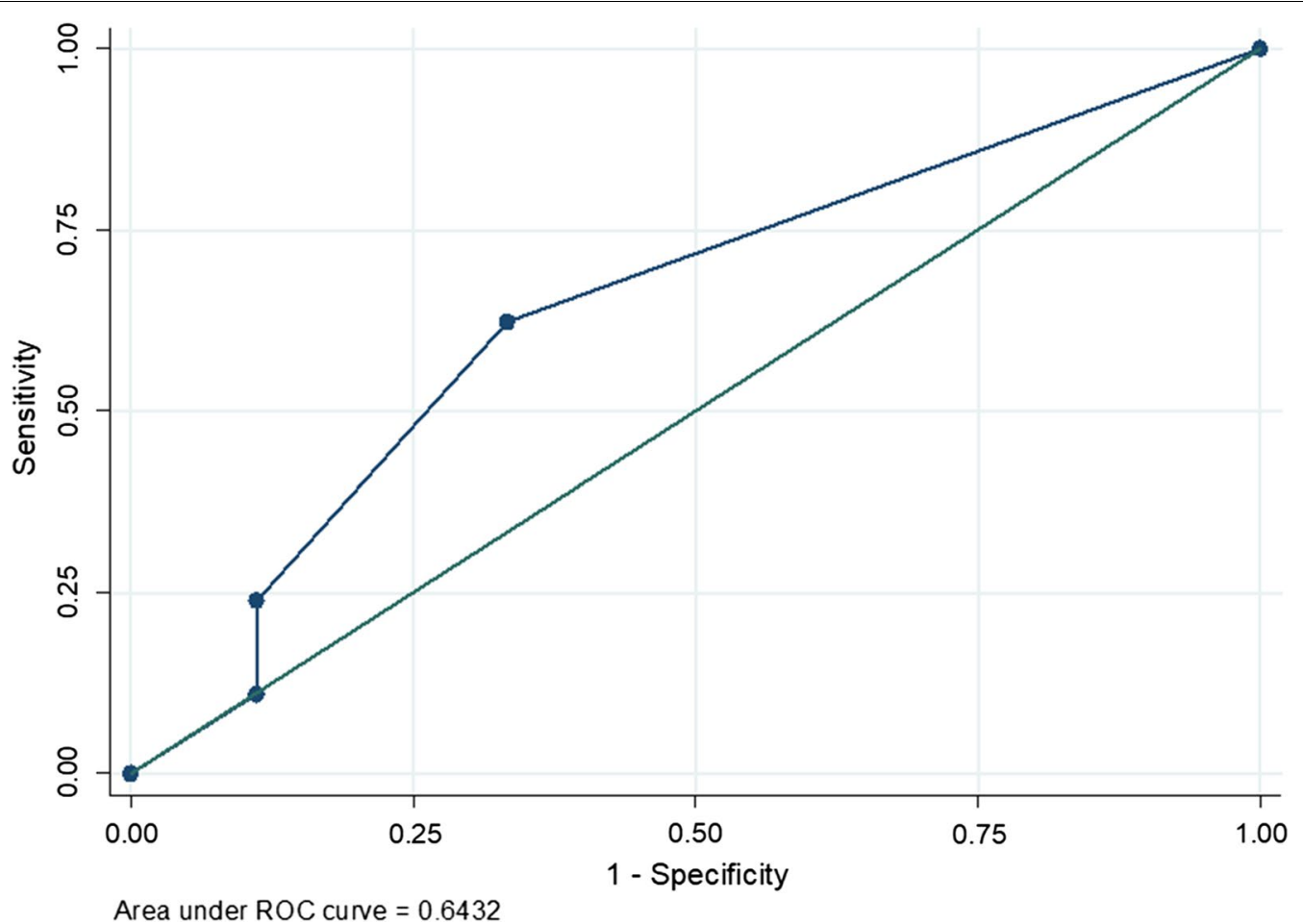

Fig. 2 ROC of $24 \mathrm{~h}$ serum lactate levels following major abdominal surgery to predict surgical site infection. AUROC was 0.6432 
Table 4 Factors associated with surgical site infection among patients who underwent major abdominal surgery at MNRH during the study period

\begin{tabular}{|c|c|c|c|c|c|c|}
\hline \multirow[t]{2}{*}{ Characteristic } & \multicolumn{3}{|c|}{ Univariate } & \multicolumn{3}{|c|}{ Multivariate } \\
\hline & cOR & $95 \% \mathrm{Cl}$ & p-value & $\mathrm{aOR}$ & $95 \% \mathrm{Cl}$ & p-value \\
\hline \multicolumn{7}{|l|}{ Age } \\
\hline$<18$ years & 1 & & & & & \\
\hline$\geq 18$ years & 2.70 & $1.94-3.75$ & $<0.001$ & 1.41 & $0.58-3.45$ & 0.455 \\
\hline \multicolumn{7}{|l|}{ Type of surgery } \\
\hline Elective & 1 & & & & & \\
\hline Emergency & 2.51 & $1.88-3.36$ & $<0.001$ & 1.33 & $0.55-3.21$ & 0.521 \\
\hline \multicolumn{7}{|l|}{ ASA status } \\
\hline 1 & 1 & & & & & \\
\hline$\|$ & 0.78 & $0.44-1.26$ & 0.675 & 0.79 & $0.74-2.14$ & 0.389 \\
\hline III & 1.42 & $0.95-4.55$ & 0.080 & 1.10 & $0.23-1.98$ & 0.078 \\
\hline IV & 3.64 & $1.59-7.65$ & 0.042 & 2.60 & $0.81-3.78$ & 0.090 \\
\hline \multicolumn{7}{|c|}{$\begin{array}{l}\text { Duration between diagnosis and } \\
\text { surgery (days) }\end{array}$} \\
\hline Within 1 day & 1 & & & & & \\
\hline Longer than a day & 3.23 & $2.05-5.07$ & $<0.001$ & 1.69 & $0.57-4.99$ & 0.345 \\
\hline \multicolumn{7}{|l|}{ Duration of surgery (hours) } \\
\hline$\leq 1.5$ & 1 & & & & & \\
\hline$>1.5$ & 2.98 & $1.93-4.60$ & $<0.001$ & 1.63 & $0.63-4.35$ & 0.307 \\
\hline \multicolumn{7}{|l|}{ Pre-surgery treatment } \\
\hline Yes & 1 & & & & & \\
\hline No & 4.65 & $2.91-7.44$ & $<0.001$ & 6.20 & $1.12-4.26$ & 0.036 \\
\hline \multicolumn{7}{|l|}{ Intra operative care (litres) } \\
\hline$\leq 1$ & 1 & & & & & \\
\hline$>1$ & 0.37 & $0.25-0.58$ & $<0.001$ & 0.81 & $0.18-3.58$ & 0.780 \\
\hline \multicolumn{7}{|l|}{ Comorbidities } \\
\hline No & 1 & & & & & \\
\hline Yes & 1.13 & $1.09-1.17$ & $<0.001$ & 1.01 & $0.84-1.22$ & 0.894 \\
\hline \multicolumn{7}{|l|}{ Organs involved } \\
\hline One organ & 1 & & & & & \\
\hline More than one organ & 3.35 & $1.16-5.46$ & $<0.001$ & 1.02 & $0.81-1.28$ & 0.873 \\
\hline \multicolumn{7}{|l|}{ Serum lactate } \\
\hline Normal ( $\leq 2.0 \mathrm{mmol} / \mathrm{L})$ & 1 & & & & & \\
\hline High (> 2.0 mmol/L) & 2.87 & $1.99-4.13$ & $<0.001$ & 1.25 & $1.11-3.70$ & 0.008 \\
\hline
\end{tabular}

The bold was indicative of the statistically significant $\mathbf{p}$ values of different variables

SSI $n=36 ; 14.6 \%$

The average lactate values between age groups were $3.18 \pm 0.44$ for patients less than 18 years and $2.74 \pm 0.24$ for those above 18 years. The difference in average values between the age groups was minimal and this reflects the ability of serum lactate to indiscriminatively predict hypoperfusion across various ages.

\section{Outcomes}

\section{In-hospital mortality}

This study observed that 34 patients died (13.8\%), a mortality rate similar to that found in a study done in MNRH by Kitara et al. who found a moratlity rate of about $14.5 \%$ [10]. Our study showed that elevated serum lactate was strongly associated with mortality with aOR 5.2 95\% CI 1.51-17.92, p-value 0.009 which is in agreement with what Velickovic et al. observed in a study done in Europe and Okello et al. observed in Uganda at MNRH $[8,12]$. Elevated serum lactate had a sensitivity $35.29 \%$, 
Table 5 Factors associated with length of hospital stay among patients who underwent major abdominal surgery at MNRH during the study period

\begin{tabular}{|c|c|c|c|c|c|c|}
\hline \multirow[t]{2}{*}{ Characteristic } & \multicolumn{3}{|c|}{ Univariate } & \multicolumn{3}{|c|}{ Multivariate } \\
\hline & cOR & $95 \% \mathrm{Cl}$ & p-value & $\mathrm{aOR}$ & $95 \% \mathrm{Cl}$ & p-value \\
\hline \multicolumn{7}{|l|}{ Age } \\
\hline$<18$ years & 1 & & & & & \\
\hline$\geq 18$ years & 5.11 & $2.40-6.49$ & $<0.001$ & 3.47 & $0.08-0.66$ & 0.390 \\
\hline \multicolumn{7}{|l|}{ Gender } \\
\hline Male & 1 & & & & & \\
\hline Female & 3.27 & $2.64-3.90$ & $<0.001$ & 2.03 & $0.63-6.62$ & 0.237 \\
\hline \multicolumn{7}{|l|}{ Type of surgery } \\
\hline Elective & 1 & & & & & \\
\hline Emergency & 2.82 & $2.33-3.31$ & $<0.001$ & 2.64 & $0.64-3.20$ & 0.737 \\
\hline \multicolumn{7}{|l|}{ ASA status } \\
\hline I & 1 & & & & & \\
\hline$\|$ & 4.12 & $2.76-5.49$ & $<0.001$ & 2.22 & $0.43-5.67$ & 0.316 \\
\hline III & 7.41 & $5.82-8.99$ & $<0.001$ & 6.28 & $2.74-8.97$ & 0.003 \\
\hline IV & 3.00 & $4.27-10.27$ & 0.416 & 1.86 & $0.20-2.35$ & 0.960 \\
\hline \multicolumn{7}{|c|}{$\begin{array}{l}\text { Duration between diagnosis \& treatment } \\
\text { for emergencies (days) }\end{array}$} \\
\hline Within 1 day & 1 & & & & & \\
\hline Longer than a day & 3.67 & $3.00-4.34$ & $<0.001$ & 2.54 & $0.08-3.16$ & 0.508 \\
\hline \multicolumn{7}{|l|}{ Duration of surgery (hours) } \\
\hline$\leq 1.5$ & 1 & & & & & \\
\hline$>1.5$ & 3.45 & $2.96-3.93$ & $<0.001$ & 2.03 & $1.91-3.15$ & 0.032 \\
\hline \multicolumn{7}{|l|}{ Pre-surgery treatment } \\
\hline Yes & 1 & & & & & \\
\hline No & 3.81 & $3.08-4.53$ & $<0.001$ & 1.13 & $0.60-5.86$ & 0.637 \\
\hline \multicolumn{7}{|l|}{ Comorbidities } \\
\hline No & 1 & & & & & \\
\hline Yes & 2.35 & $1.29-4.42$ & $<0.001$ & 1.90 & $0.27-2.12$ & 0.446 \\
\hline \multicolumn{7}{|l|}{ Organs involved } \\
\hline One organ & 1 & & & & & \\
\hline More than one organ & 0.75 & $0.60-0.89$ & $<0.001$ & 0.24 & $0.16-2.32$ & 0.800 \\
\hline \multicolumn{7}{|l|}{ Serum lactate } \\
\hline Normal ( $\leq 2.0 \mathrm{mmol} / \mathrm{L})$ & 1 & & & & & \\
\hline High (> 2.0 mmol/L) & 5.34 & $3.86-6.82$ & $<0.001$ & 1.75 & $1.43-2.37$ & 0.043 \\
\hline
\end{tabular}

The bold was indicative of the statistically significant $\mathbf{p}$ values of different variables

specificity $96.26 \%$, PPV $60 \%$, NPV $90.35 \%$ proving it is a reliable biomarker, in agreement with other studies $[8,12$, 13].

The ROC analysis demonstrated that elevated serum lactate was accurate in predicting in-hospital mortality and that the $24 \mathrm{~h}$ serum lactate levels had the best

Table 6 Average length of hospital stay over serum lactate levels

\begin{tabular}{llll}
\hline Lactate/hospital stay & Mean in days & SD & $\mathbf{9 5 \% ~ C l}$ \\
\hline$\leq 2 \mathrm{mmol} / \mathrm{L}$ & 5.12 & 0.55 & $4.04-6.20$ \\
$>2 \mathrm{mmol} / \mathrm{L}$ & 5.34 & 0.69 & $3.98-6.71$ \\
\hline
\end{tabular}

AUROC of 0.7898 which corresponds to good accuracy. These findings were similar to those in studies that were done in MNRH in trauma patients [12] and one done in Europe in elective patients post major abdominal surgery that had AUROC of 0.821 [8].

Statistically, the following factors increased the risk of mortality; patients with comorbidities p-value $<0.001$, especially in the setting of hypoperfusion, similar to what was observed by Lars et al. [11]. The duration of surgery $\geq 1.5 \mathrm{~h}$ p-value 0.049 which could be attributed to the duration of tissue manipulation and as such compounding the hypoperfusion 
of the patients and result in elevation of serum lactate levels. The delay between diagnosis and surgery greater than a day had a p-value 0.003 resulting in delay to remove the insult that could be causing the hypoperfusion though this is usually attributed to logistical delays and finally age $>18$ years usually corresponding to more critically ill patients had a p-value of 0.034 similar to what other studies noted $[8,12]$.

\section{Surgical site infection}

In this study, $14.6 \%$ of the patients developed surgical site infections. These findings were similar to rate of $14.1 \%$ that was observed in MNRH [10].

Consistent with studies by Velickovic et al., Cobianchi et al. and Bakker et al. $[8,14,15]$, it was observed that elevated serum lactate was significantly associated with surgical site infection with an aOR 1.25 95\%CI 1.11-3.72, p-value 0.008 . Elevated serum lactate had a sensitivity of $94.4 \%$, specificity of $54.3 \%$ and the accuracy of predicting SSI being sufficient at 0.6432 AUROC. In this study the accuracy for predicting SSI was sufficient in comparison to a study done in Europe [8], where the AUROC was 0.787 . The difference in accuracy could be attributed to difference in geographical location of the two studies, which brings into consideration different antibiotic guidelines as well as pathogens responsible for SSI.

Patients not receiving pre-operative antibiotics, potentiating the risk of developing surgical site infection, would explain why lack of pre-surgery treatment was a significant factor with p-value of 0.036 as observed in our study.

\section{Length of hospital stay}

Length of hospital stay was associated withsurgical site infection and this was in keeping with a study by Seni et al. done at MNRH that looked at antimicrobial resistance in hospitalised surgical patients [16].

Patients with elevated serum lactate on average had a longer length of hospital stay at $5.34 \pm 0.69$ as compared to those that had normal lactate levels. Elevated serum lactate was associated with a longer length of hospital stay, with a $\mathrm{p}$ value of 0.043 , consistent with other studies $[7,8,17]$ though their patients had a longer length of stay compared to those in our study. This could be attributed to the volume of patients admitted to MNRH versus availability of space for admission of patients and therefore high turnover of patients.

In our study, patients that had duration of surgery $>1.5 \mathrm{~h}$ and ASA III were more likely to have longer duration of hospital stay with significant p-value of $<0.05$. This can be explained by these patients being were more critically ill, having had longer periods of time of tissue manipulation intraoperatively and more severe forms of comorbidity present.

\section{Limitations}

The study was carried out at tertiary health facility receiving referrals which could have caused random error especially at the time of sampling. Logistical delays that were out of our control especially erratic supply of necessities for surgery.

\section{Conclusion}

Elevated serum lactate was associated with in-hospital mortality, surgical site infection and longer length of hospital stay. Serum lactate levels done at $24 \mathrm{~h}$ were most predictive mortality and surgical site infection compared to the other perioperative serum lactate levels.

\section{Abbreviations \\ ASA: American Association of Anaesthesiologists; ASOS: African Surgical Outcome Study; AUROC: Area Under Receiver Operator Curve; MNRH: Mulago National Referral Hospital; POCs: Post Operative Complications; SSC: Surviving Sepsis Campaign; SSI: Surgical Site Infection.}

\section{Acknowledgements}

We would like to appreciate all the patients and their caretakers for participating in this study. We also thank our research assistants for their unwavering dedication to the success of the study.

\section{Authors' contributions}

All authors read and approved the final manuscript.

Funding

This work was self-funded by the authors

Availability of data and materials

Data sets are available by friendly request to the corresponding author.

\section{Declarations}

Ethics approval and consent to participate

Ethical approval was obtained on the 22nd of July 2019 from Makerere University College of Health Science, Research and Ethics Committee-\# REC REF 2019-094. A written informed consent was obtained for the participants. Informed consent was obtained from a parent or legal guardian for a participant under 18 years of age.

Consent of publication

All participants consented for publication of the results of the study.

Competing interests

All authors declared they had no competing interests.

\section{Author details}

'Department of Surgery, College of Health Sciences, Makerere University, Kampala, Uganda. ${ }^{2}$ Department of Surgery, Mulago National Referral Hospital, Kampala, Uganda.

Received: 27 March 2021 Accepted: 20 July 2021

Published online: 07 August 2021 


\section{References}

1. Weiser TG, Regenbogen SE, Thompson KD, Haynes AB, Lipsitz SR, Berry WR, et al. An estimation of the global volume of surgery: a modelling strategy based on available data. The Lancet. 2008;372(9633):139-44.

2. Meara JG, Leather AJ, Hagander L, Alkire BC, Alonso N, Ameh EA, et al. Global Surgery 2030: evidence and solutions for achieving health, welfare, and economic development. The Lancet. 2015;386(9993):569-624.

3. Galukande M, von Schreeb J, Wladis A, Mbembati N, de Miranda H, Kruk $M E$, et al. Essential surgery at the district hospital: a retrospective descriptive analysis in three African countries. PLoS Med. 2010;7(3):e1000243.

4. Jhanji S, Lee C, Watson D, Hinds C, Pearse RM. Microvascular flow and tissue oxygenation after major abdominal surgery: association with postoperative complications. Intensive Care Med. 2009;35(4):671-7.

5. Gunnerson KJ, Pinsky M. Lactic acidosis. Medscape Reference. 2011. https://emedicine.medscape.com/article/167027-overview

6. Nicks BA, McGinnis H, Borron S, Mégarbane B. Lactic acidosis. eMedicine. 2008. https://emedicine.medscape.com/article/768159-overview

7. Chebl RB, El Khuri C, Shami A, Rajha E, Faris N, Bachir R, et al. Serum lactate is an independent predictor of hospital mortality in critically ill patients in the emergency department: a retrospective study. Scand J Trauma Resusc Emerg Med. 2017;25(1):69.

8. Velickovic J, Milicic B, Palibrk I, Djukanovic M, Velickovic D, Marjanovic S. Prognostic value of postoperative lactate levels in predicting complications after major abdominal surgery: 1AP3-5. Eur J Anaesthesiol (EJA). 2014:31:11.

9. Haanschoten MC, Kreeftenberg HG, Bouwman RA, van Straten $A H$, Buhre WF, Hamad MAS. Use of postoperative peak arterial lactate level to predict outcome after cardiac surgery. J Cardiothorac Vasc Anesth. 2017:31(1):45-53.
10. Kitara D, Kakande I, Mugisa B, Obol J. The postoperative complications prediction in Mulago Hospital using POSSUM scoring system. East Cent Afr J Surg. 2010;15(2):90-6.

11. Andersen LW, Mackenhauer J, Roberts JC, Berg KM, Cocchi MN, Donnino MW, editors. Etiology and therapeutic approach to elevated lactate levels. Mayo Clinic Proceedings; 2013: Elsevier.

12. Okello M, Makobore P, Wangoda R, Upoki A, Galukande M. Serum lactate as a predictor of early outcomes among trauma patients in Uganda. Int J Emerg Med. 2014;7(1):20.

13. Kintu-Luwaga R, Galukande M, Owori FN. Serum lactate and phosphate as biomarkers of intestinal ischemia in a Ugandan tertiary hospital: a cross-sectional study. Int J Emerg Med. 2013;6(1):44.

14. Cobianchi L, Peloso A, Filisetti C, Mojoli F, Sciutti F. Serum lactate level as a useful predictor of clinical outcome after surgery: an unfulfilled potential? J Thorac Dis. 2016;8(5):E295.

15. Bakker J, De Lima AP. Increased blood lacate levels: an important warning signal in surgical practice. Crit Care. 2004;8(2):96.

16. Seni J, Najjuka CF, Kateete DP, Makobore P, Joloba ML, Kajumbula H, et al. Antimicrobial resistance in hospitalized surgical patients: a silently emerging public health concern in Uganda. BMC Res Notes. 2013;6(1):298.

17. Rhodes A, Evans LE, Alhazzani W, Levy MM, Antonelli M, Ferrer R, et al. Surviving sepsis campaign: international guidelines for management of sepsis and septic shock: 2016. Intensive Care Med. 2017;43(3):304-77.

\section{Publisher's Note}

Springer Nature remains neutral with regard to jurisdictional claims in published maps and institutional affiliations.
Ready to submit your research? Choose BMC and benefit from:

- fast, convenient online submission

- thorough peer review by experienced researchers in your field

- rapid publication on acceptance

- support for research data, including large and complex data types

- gold Open Access which fosters wider collaboration and increased citations

- maximum visibility for your research: over $100 \mathrm{M}$ website views per year

At BMC, research is always in progress.

Learn more biomedcentral.com/submissions 